\title{
The Perception of the City and the Village by Russian and Chinese Young Adults
}

\author{
Dina F. Mymrina - Svetlana L. Vasilyeva - Anastasia L. \\ Khlebnikova - Olga M. Zubkova - Sofia A. Chizhevskaya
}

\section{DOI: 10.18355/XL.2016.09.04.116-131}

\begin{abstract}
In the present-day society, the process of urbanization is often seen as one of the global tendencies that may bring about immense positive and negative changes in the lives of people. It appears that urbanization is largely associated with rural-urban migration, which may affect the economies of towns, cities, and rural areas globally. It tends to be that the youth are a significant part of this migration process. To better understand the problem, attempts have been made to investigate the factors responsible for the youth migration through revealing the attitude of the youth to modern city and village. This was done with the help of a free association experiment, focusing on similarities and differences in the city and the village perception by Russian and Chinese young people. As a result, specific socio-cultural factors and differences in the city and the village perception among the youth were revealed, some of the causes of the undergoing territorial and social transformations were identified, which may allow predicting the prospects of the city and the village development in future.
\end{abstract}

Key words: Urbanization, rural-urban migration, the image of the city, the image of the village, free association experiment, sociolinguistics

\section{Introduction}

The $21^{\text {st }}$ century is often related to the phenomenon of rapid urbanization. In 2008 , for the first time in human history, the number of people living in urban areas surpassed the number living in rural areas. According to the UN report on world urbanization prospects, in July $2014,54 \%$ of the world's population lived in urban areas, and it is expected that by $205066 \%$ of the world's population will be urban (2014: 1).

The growth of the urban population is largely associated with economic benefits that urban living can bring. It is true that cities concentrate much of the transportation, commerce, and cultural activities, provide greater access to better health services and education, thus offering a higher standard of living compared with rural areas. People frequently migrate to cities in search of employment; they are often attracted by better economic prospects and better opportunities for self-realization and personal development that cities offer. Modern cities cannot be imagined without art, libraries, theaters, museums, concert halls, parks, etc. Last but not least, urban living allows one to effectively organize one's free time. As a result, cities appear to offer more favorable living conditions as compared to rural areas. However, it is well known that under certain conditions the growth of urban areas may lead to negative consequences. One of these negative consequences is inequalities that exist within cities. This can be proved by the fact that at present millions of urban dwellers worldwide live in poverty. In some cases, irrational urban policy leads to urban sprawl or a large number of environmental problems such as air, water and noise pollution, traffic congestion, etc. Negative processes such as drug addiction, organized crime, child neglect are also often associated with cities. Nevertheless, it appears that negative aspects of city living do not often stop people from migrating to urban areas. 
Nowadays, the process of urbanization is often viewed as one of the key tendencies characterizing modern society; as a result, the problem of urban and rural areas and their representation in the public consciousness appear to become of crucial importance in recent humanitarian interdisciplinary studies. Growing importance of cities, rural-urban migration and the changes that it brings about in public consciousness are often studied by economists, geographers, psychologists, sociologists, and linguists. Some of these studies are concerned with the problems of the city's image and its elements (Kevin Lynch, 1960; Avraham 2004; Evans and Show, 2004; Garcia, 2004, 2005; Dinnie, 2010; Duncan and Ley, 2013), the influence of the city's history, values and attitudes on the city's image, emotional attitude towards urban areas (Strauss, 1968; Van der Ryn, 1963; Pile, 2010; Slater and Anderson, 2012), the impact of age, gender, occupation on the perception of the city (Appleyard, 1970). Very often, the studies of urbanization are not limited to the analysis of urban areas and characteristics of urban living. On the opposite, they often focus on rural areas and the village (Connell, Dasgupta, Laishley and Lipton, 1976; Firebaugh, 1979; Korel, 1982; Arutyunyan, 1995; Chizhikov, 1999; Zegar, 2009; Grigoriev, 2010; Shkerin, 2012). A number of studies are devoted to the problem of internal migration, including rural-urban migration (Tarasova, 1995; Golovaschenko, 1996; Akhiezer, 2000; Mkrtchyan, 2003; Florinskaya, 2006; Nikiforov, 2007; Patsiorkovskii, 2010), etc.

This paper, which is part of a series of articles devoted to the sociolinguistic studies of the city (Mymrina, Abdrashitova, 2015), focuses on the possible causes of rural-urban migration that is currently taking place in most of the countries, including Russia and China. Through the linguistic analysis, thus, by investigating the specific perception of the city and the village by Russian and Chinese young people, we aim to reveal the reasons for present-day youth migration from small towns and rural areas to big cities and megalopolises.

\section{Materials and methods}

The research lies at the intersection of linguistics and sociology and studies the problem of the urban and rural population ratio by interpreting associative responses of respondents to the words-stimuli CITY and VILLAGE. The aim of the article is to identify the characteristics of the city and the village perception by Russian and Chinese young people with a special emphasis on the emotional and pragmatic attitude of the respondents to the places under study.

\subsection{Method}

The study relies on the material obtained in an experimental test, namely a free association experiment or word association test, which focuses on the perception of the fragment of reality, which is the most relevant at the moment of speech. Association experiments, which are widely used in psychology, sociology, psychiatry, psycholinguistics, etc. are often thought to provide access to public consciousness and allow researchers to reveal the details of perception of a fragment of reality which are typical of an average culture bearer, his motifs and priorities (Ufimtseva, 1996: 140), which is seen as one of the objectives of the present study. In a free association experiment, respondents are normally asked to provide word / words that come to their mind after they think over a word stimulus given to them (respondents are not limited in the type or number of verbal responses they may provide). Analyzing the frequency of reactions given, researchers can draw a conclusion on their relevance / irrelevance to the respondents. It is often true that the data obtained in a free association experiment are an important source of information for cross-cultural studies which may also reveal the forms of axiological perception of the world, factors that determine people's behaviour and spiritual / material culture of the people. 
Applying a free association experiment to identify the specifics of the city and the village perception by Russian and Chinese young adults, we aim to reveal similar tendencies within the cultures studied. First of all, it is due to the fact that Russian and Chinese dictionary definitions of a city and a village are very much similar with a slight difference concerning the fact that the Chinese dictionary puts emphases on the city's and village's population density which is fully understandable and may be easily explained by the objective criteria. So, according to "Modern Dictionary of the Russian Language" by S. I. Ozhegov, a city is "a large settlement; an administrative, industrial, commercial and cultural center”. In Chinese, 城市 (chéng shì) is defined as "densely-populated area with developed industry and trade, which is usually a political, economic and cultural center of a region" (http://www.ichacha.net/hy/\%E4\%B9\%A1\%E6\%9D\%91.html). Dictionary definitions of a village are also very much alike. So, "the Big Soviet Encyclopedia" defines a village as a small agricultural settlement, whose inhabitants are mostly farmers and farm workers." (http://www.bigsoviet.ru/165/24777/\%D0\%94\%D0\%B5\%D1\%80\%D0\%B5\%D0\%B2\%D0\%BD\%D1 \%8F). In Chinese, 乡村(xiāngcūn) has the following characteristic feature: its residents are mainly engaged in agriculture; and the population density here is much lower compared to cities (http://www.ichacha.net/hy/\%E4\%B9\%A1\%E6\%9D\%91.html). Thus, apart from the population density mentioned above the definitions contain the same lexemes in both languages identifying the city with a political and industrial center and associating the village with agriculture and subsistence farming. On the other hand, it is expected that the study may also reveal some differences in the perception of the city and the village that are socially and culturally predetermined, though these differences may not be profound due to the global character of modern culture.

With the aim of revealing the specifics of the attitude to the city and the village, Russian and Chinese respondents were presented with the words-stimuli CITY and VILLAGE in the written form and were asked to give word / words that come to mind after they thought about the stimuli given to them. The respondents were free to include any reactions, belonging to different parts of speech, reactions-phrases, sentences, etc., thus, they were not limited in the type or number of verbal responses they could provide. The analysis of the associative reactions obtained allows revealing similarities and differences in the perception of the city and the village by Russian and Chinese young people, identifying the objects, which are socially important for the respondents, which makes it possible to predict the character and direction of their activity, and evaluate the prospects of urban and rural development in future.

\subsection{Participants}

The participants are 40 students between 18 and 26 years old, including 20 Russian second-year students of Tomsk State University of Architecture and Building (TSUAB) and 20 Chinese third-year - fifth-year students of National Research Tomsk Polytechnic University (TPU), participating in the TPU academic exchange programmes. The choice of the two groups of participants allows us to determine the factors that underlie the similarities, which are possibly due to processes of globalization, in the city and the village perception by the youth as well as the differences, which may be culturally-predetermined.

\subsection{Materials}

The material of the research are 479 and 510 associative reactions provided by the Chinese and Russian students respectively in response to the words-stimuli CITY and VILLAGE. The reactions obtained represent the associative relationships in the 
consciousness of the respondents and, in bulk, give the idea of the objects described and reveal the image of the city and the village.

During the experiment the participants were not limited in the ways of giving reactions, were free in their choice of lexical units and relied only on their own experience and personal view of the city and the village.

\subsection{Procedure}

In the free association experiment, the respondents were presented with the words-stimuli CITY and VILLAGE in the written form and were instructed to supply words that first came to their mind. The words-stimuli were written in the middle of the page and were followed by a blank space in which participants had to write the first words that they could think of. The participants were given 20 minutes to supply their responses. The experiment was conducted in the students' classrooms at TPU and TSUAB. The respondents were asked neither to talk nor to somehow react during the test.

After the experiment, all the obtained reactions of the respondents were counted, ranked according to the degree of frequency and analyzed in terms of various parameters, including pragmatic and emotional ones.

\section{Results and discussions}

Analyzing associations to CITY and VILLAGE, we take into account that the present study focuses on the views of the fragments of the world characteristic of the bearers of the Russian and Chinese cultures which are reflected in verbal associations. So, we expect that together with the specifics of the world perception the study may reveal some of the tendencies that make today's society more globalised than ever.

So, firstly, let us consider the image of the city represented in the Russian and Chinese participants' consciousness. The total number of responses to the wordstimulus $C I T Y$ provided by the Russian respondents in the free association experiment is 278; 40 out of them are single-individual responses. As for the Chinese participants, they gave 282 responses, 15 out of which were single-individual. In both cases no refusals to provide reactions were recorded.

The results of the free association experiment are shown in Table 1, which demonstrates the features which were most often associated with the city. Further on the frequency of different reactions will be shown in brackets.

\section{Table 1. The responses (associations) to the word-stimulus CITY}

\begin{tabular}{|c|c|}
\hline Russian young adults & Chinese young adults \\
\hline $\begin{array}{l}\text { Traffic jams (20), pollution (17), jobs } \\
\text { and career (16), education (15), } \\
\text { recreation and entertainment (14), } \\
\text { opportunities (13), supermarkets (13), } \\
\text { high buildings (13), noise (12), } \\
\text { developed infrastructure (9), many cars } \\
\text { (8), meeting new people (5), civilization } \\
\text { (5), rush (5), lack of time (4), } \\
\text { dependence on money (4), money (4), } \\
\text { timely medical aid (4), lack of time (4), } \\
\text { everything is near (3), beautiful (3), } \\
\text { comfortable (3), routine (3), depression } \\
\text { (3), diseases (3), convenient (3), great } \\
\text { (2), stresses (2), evil people (2), parks }\end{array}$ & $\begin{array}{l}\text { Environmental pollution (18), people } \\
\text { (16), convenient transport (14), jobs } \\
\text { (14), university (12), traffic jams (12), } \\
\text { shops (10), buildings (10), a lot of } \\
\text { rubbish (10), noise (8), cars (8), } \\
\text { stadium (8), museum (8), park (8), big } \\
\text { (8), psychological pressure (8), } \\
\text { beautiful (8), delicious food (8), } \\
\text { education (8), good clothes (6), school } \\
\text { (6), trendy (6), supermarket (6), } \\
\text { dwelling problems (6), good life (4), } \\
\text { native (4), modern (4), comfortable (4), } \\
\text { convenient (4), more opportunities to } \\
\text { have a good time (4), administration }\end{array}$ \\
\hline
\end{tabular}

XLinguae Journal, Volume 9 Issue 4, October 2016, ISSN 1337-8384 
(2), transport (2), clean (2), facilities provided (2), museums (2), theatres (2), accessibility (2), dwelling problems (2), car accidents (2), nervous (1), danger (1), prices (1), conflicts with people (1), tough people (1), selfish people (1), good roads (1), hot water (1), libraries (1), hospitals (1), poor food quality (1), interesting (1), hazards (fire, electricity, etc.) (1), there is no unity with nature (1), little verdure (1), dust (1), competent specialists (1), innovations (1), great facilities (1), cool cars (1), modern architecture (1), fast pace of life (1), etc.
(3), unhealthy lifestyle (3), trouble (2), more opportunities (1), information (1), a higher salary (1), an opportunity to meet people (1), communication (1), market (1), bus (1), river (1), street (1), science (1), family (1), zoo (1), culture (1), architecture (1), flat (1), administration (1), unhealthy life style (1), active lifestyle (1), etc.

According to the results obtained, the Russian respondents' reactions appear to be more varied as they tend to more often appeal to their individual experience, which could be proved by a greater number of single-individual associations in comparison with the Chinese students (40:15). At the same time, the Russian and Chinese respondents show some similarity in the frequency of their reactions. So, the most frequent reaction of the Chinese students to the word-stimulus CITY is environmental pollution (18), while for the Russian students it is traffic jams (20), which indicates a fundamentally different perception of the city compared with traditional definitions, found in dictionaries, including those mentioned above. It seems to be that $90 \%$ of the Chinese and $100 \%$ of the Russian young people primarily associate the city with its most crucial problems and this is the idea that brings together these two different from the first sight most frequent reactions of the Russian and Chinese respondents. However, further responses are slightly different. For instance, the Chinese respondents also associate the city with a place where a large number of people live, with the second most frequent reaction being people (16). It is obvious that this response has much in common with the Chinese dictionary definition of the city and correlates with the objective reality. On the other hand, the Russian respondents associate the city with opportunities for self-development, education, career, recreation and entertainment. According to the data obtained, the most frequent associations of the Russian young adults to the word-stimulus CITY are jobs and career (16), education (15), recreation and entertainment (14), opportunities (13), supermarkets (13), high buildings (13). It is necessary to mention that the Chinese students also associate the city with jobs (14); at the same time, they place little importance on entertainment: only 4 respondents have included the association more opportunities to have a good time into their association list. It is also interesting that the Chinese young adults are more precise in their associations, which can be exemplified by the frequency of reactions dealing with the elements of the city infrastructure: university (12), shops (10), buildings (10), cars (8), stadium (8), museum (8), park (8), school (6), etc. In some instances, they evaluate the usefulness and benefits of these elements by giving a) collocations containing descriptive attributes: convenient transport (14), delicious food (8), good clothes (6), a higher salary (1); or b) adjectives with positive connotation: big (8), beautiful (8), trendy (6), native (4), modern (4), comfortable (4), convenient (4). Apart from mentioned above the Russian respondents point out such advantages of city life as developed infrastructure (9), many cars (8), meeting new people (5), civilization (5), money (4), timely medical aid (4), everything is near (3), facilities provided (2). At the same time 
the Russian participants are not as unanimous as the Chinese ones in their attributebased associations thus giving single-individual or rare responses of that kind: beautiful (8), comfortable (4), great (2), clean (2), interesting (1). On the whole, it appears that despite the variety of the reactions given, they manage to create a unique rather positive image of the city which is mainly associated by both Chinese and Russian respondents with the opportunities for self-expression, communication as well as comfortable environment.

On the other hand, as far as emotional perception is regarded, it may be claimed that negative associations to CITY are also rather frequent. Apart from the abovementioned traffic congestion and environmental problems, the Chinese participants speak about psychological pressure (8) and unhealthy lifestyle (3), which are especially characteristic of urban living. These correspond to the Russian young adults' associations such as depression (3), diseases (3), and stresses (2). On the whole, the Russian respondents list a larger number of negative effects, related to city living. All these negative effects are the result of the poor environment, time pressure and rapid lifestyle, which obviously can adversely affect a person's living in the city: rush (5), lack of time (4), dependence on money (4), routine (3), depression (3), diseases (3), stresses (2), evil people (2), nervous (1), danger (1), prices (1), conflicts with people (1), tough people (1), selfish people (1). Still, as it is seen from the number of reactions given in brackets, negative responses, although totally numerous, mostly represent individual associations with the city life based on personal experience and if taken separately fall to the periphery of reactions.

Figure 1 and Figure 2 show the nuclear features of the city, which were discovered in the course of the study, and demonstrate the close and remote periphery of the concept.

Figure 1. Russian young adults' associations to the word-stimulus CITY

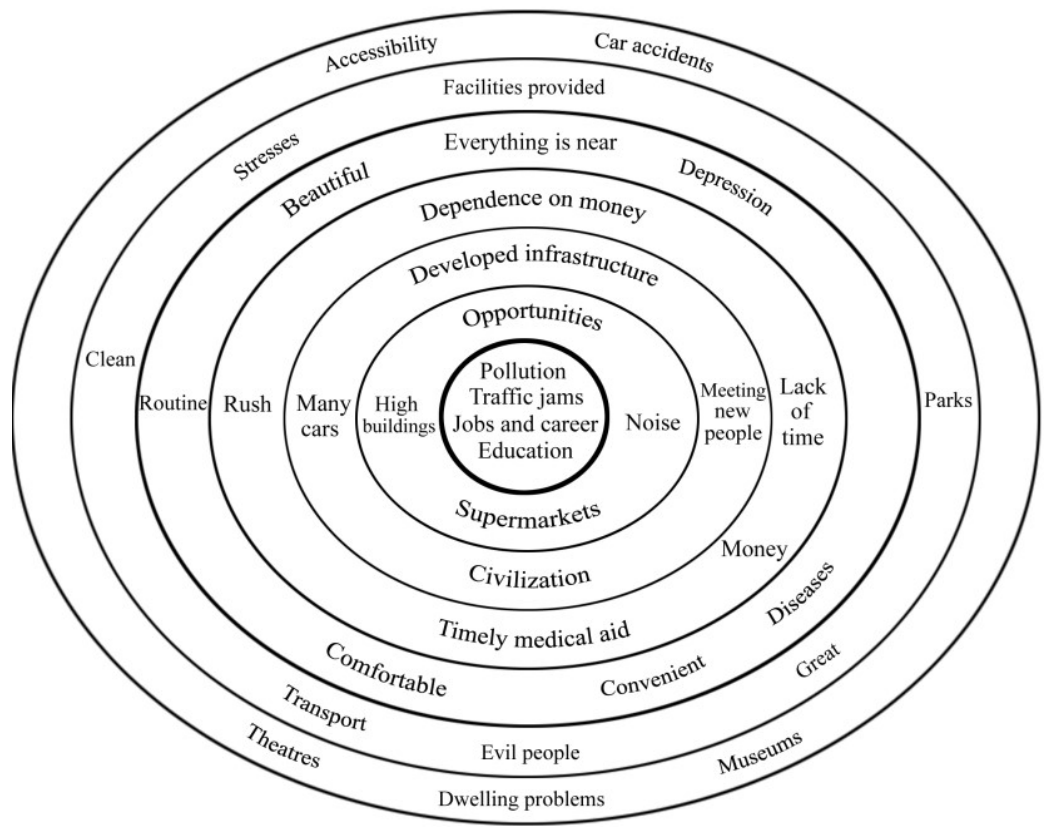


Figure 2. Chinese young adults' associations to the word-stimulus CITY

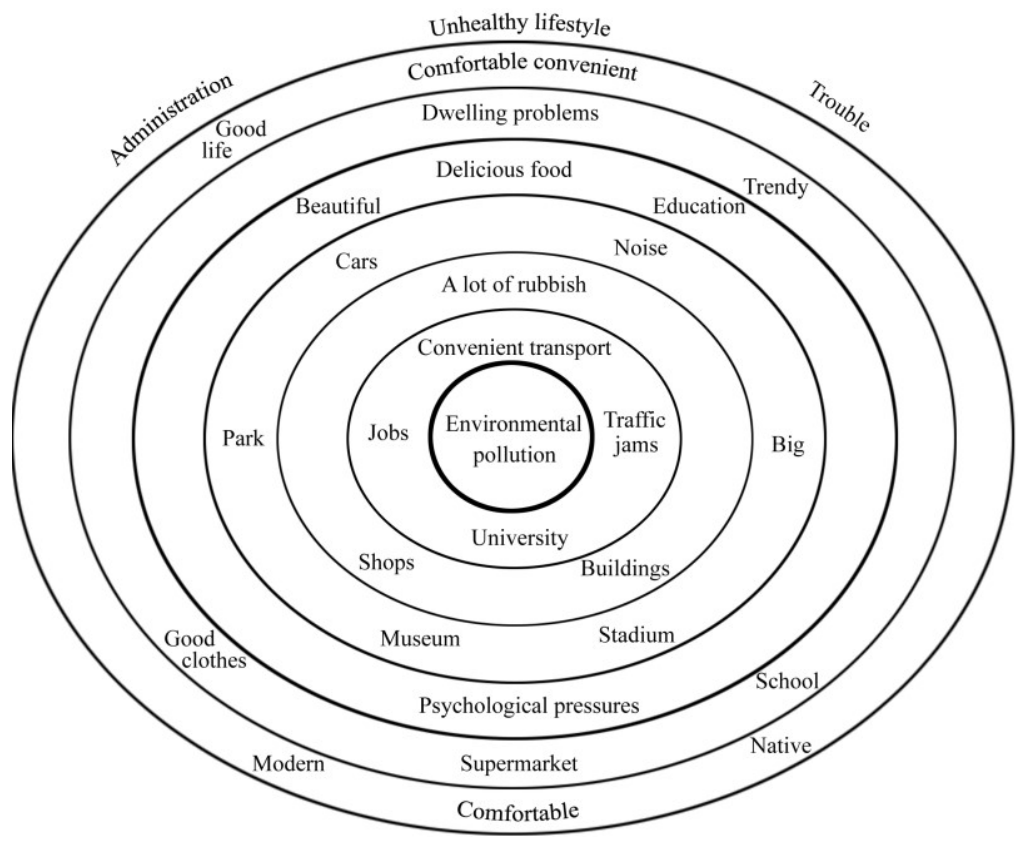

The comparison of the pragmatic perception of the city by the Russian and Chinese respondents has shown that both groups consider cities to be useful and comfortable, despite several drawbacks of urban living, mentioned above. To create a wider picture of the pragmatic attitude to the city, the results obtained have been analyzed from the standpoint of the parameters which appear to be indicative of a person's system of views concerning the advantages of city living. These parameters include characteristics of the living conditions, employment / occupation, recreation, prestige / status and the environmental factor.

So, as it was expected, living conditions have a large value both for the Russian and Chinese young adults. This can be proved by the Russian respondents' associations to CITY (58 reactions (21\%)), including: supermarkets (13), developed infrastructure (9), civilization (5), timely medical aid (4), convenient (3), everything is near (3), comfortable (3), parks (2), transport (2), clean (2), facilities provided (2), museums (2), theatres (2), accessibility (2), dwelling problems (2), good roads (1), hot water (1), libraries (1), hospitals (1), poor food quality (1). Among the Chinese respondents, associations related to the assessment of the living environment, rank first in frequency and make up $42 \%$ of the total number of reactions provided: convenient transport (14), university (12), shops (10), buildings (10), cars (8), stadium (8), delicious food (8), park (8), trendy (6), supermarket (6), good clothes (6), dwelling problems (6), modern (4), comfortable (4), administration (3), an opportunity to meet people (1), communication (1), market (1), bus (1), river (1), street (1).

Another pragmatic parameter to be discussed is the assessment of the employment / occupation. Thus, the Russian respondents have provided 62 reactions related to this parameter, which makes up $22 \%$ of the total number of the associations: jobs and career (16), education (15), opportunities (13), meeting new people (5), rush (5), lack of time (4), routine (3), fast pace of life (1). It should be noticed that together 122 
with the positive assessment of the job opportunities the Russian students mention the negative consequences of high job engagement: rush (5), lack of time (4), routine (3).The Chinese young people give fewer total associations connected with the employment parameter making all in all 40 associations to the word-stimulus ( $14 \%$ of the total number of the reactions), but the number of the most frequent responses and their content are quite similar to those of the Russian students thus showing that representatives of both cultures attach equal importance to this aspect : jobs (14), university (12), education (8), school (6).

From the point of view of prestige and status, the Russian and Chinese students' responses can correlate in content and number: 29 reactions, related to this parameter, have been received from the Russian students, which makes up $10 \%$ of the total number of the reactions, and 30 associations or $10 \%$ accordingly were provided by the Chinese students. The Russian young people mention high buildings (13), money (4), dependence on money (4), beautiful (3), great facilities (1), cool cars (1), modern architecture (1), competent specialists (1), innovations (1). The Chinese young people provide the following characteristics: trendy (6), good clothes (6), modern (4), good life (4), convenient (4), administration (3), more opportunities (1), a higher salary (1), information (1).

Judging by the associations provided, the environmental parameter is of great significance for the Russian and Chinese youth. So, 64 associations by the Russian students, or $23 \%$ of the total number, refer to the environmental problems and their consequences: traffic jams (20), pollution (17), noise (12), depression (3), diseases (3), stresses (2), car accidents (2), hazards (fire, electricity, etc.) (1), there is no unity with nature (1), little verdure (1), dust (1). 53 Chinese students' reactions, or $19 \%$ of the total number, are also associated with environmental issues: environmental pollution (18), traffic jams (12), a lot of rubbish (10), noise (8), unhealthy lifestyle (3), and trouble (2). It means that both Russian and Chinese young people fully realize the negative points of city life which are the direct results of the urbanization process as a whole.

Thus, the largest number of the Russians and Chinese respondents' pragmatic reactions are related to the characteristics of living conditions, employment and environment, which appear to be of paramount importance for today's young adult. It is crucial to notice, however, that these parameters of city life which are most significant for the respondents are indicated by opposite emotional reactions which mark living conditions and employment opportunities by positive and the environment chiefly by negative reactions, thus emphasizing the respondents' strive for the former and the necessity of reconciliation with the latter. Moreover, the analyzed data show that the Chinese students greatly appreciate the comfort and the conditions of life, provided by the city, while the Russian participants set a higher value on recreation facilities. However, the Russian and Chinese respondents coincide in their attitude towards employment / occupation, which is often thought to be the main advantage of urban living. So, it may be concluded that the Russian and Chinese students' associative-verbal reactions to CITY create a rather ambiguous image of the city. Despite this, the results of the experiment have shown that the majority of the Russian and Chinese respondents, $90 \%$ and $95 \%$, respectively, support the idea of city living, being mainly ruled by the pragmatic factors, including opportunities to find jobs and earn money as well as comfortable living conditions and much entertainment.

The second part of the research focuses on the attitude of young adults to the village. So, let us consider the reactions of the respondents to the word-stimulus VILLAGE and rank them according to their frequency. The total number of responses provided by the Russian respondents is $232 ; 42$ out of them are single-individual responses, while the Chinese participants gave 197 responses, 10 out of which are 
single-individual responses. At this stage of the experiment, in both cases no refusals to provide responses were recorded.

The results of the free association experiment are shown in Table 2, which demonstrates the features which were most often associated with the village.

Table 2. The responses (associations) to the word-stimulus VILLAGE

\begin{tabular}{|c|c|}
\hline Russian young adults & Chinese young adults \\
\hline $\begin{array}{l}\text { Fresh air (20), nature (17), tranquility } \\
\text { (10), quietness (10), natural food (7), } \\
\text { berries and mushrooms (6), little } \\
\text { opportunity for professional } \\
\text { development (5), you (one) can have a } \\
\text { rest (5), no job (4), river (4), forest (4), } \\
\text { far from civilization (3), poor medical } \\
\text { treatment (3), lack of essential things } \\
\text { (3), poor (3), poor goods supply at } \\
\text { shops (3), fresh milk (3), beauty (3), far } \\
\text { from the city (3), dirty (3), low pay (2), } \\
\text { private enterprise (2), no hot water (2), } \\
\text { fishing (2), problems with transport (1), } \\
\text { no access to up-to-date information (1), } \\
\text { few modern facilities (1), no } \\
\text { infrastructure (1), no comfortable } \\
\text { conditions (1), stupid people (1), less } \\
\text { competitive (1), independence (1), } \\
\text { festivals (1), hunting (1), outdoor } \\
\text { activities (1), fishing rod (1), fires (1), } \\
\text { buns (1), happiness (1), perfect } \\
\text { spiritual state of mind (1), monotonous } \\
\text { dull life (1), nowhere to go (1), } \\
\text { loneliness (1), etc. }\end{array}$ & $\begin{array}{l}\text { Fresh air (19), poor road (12), nature } \\
\text { (10), forest (10), river (8), } \\
\text { uncomfortable transport (8), few } \\
\text { shops (6), lake (6), trees (6), } \\
\text { sameness (6), animals (5), few cars } \\
\text { (4), problems of public health service } \\
\text { (4), no opportunities to get education } \\
\text { (4), uncomfortable (4), no job (3), } \\
\text { milk (3), slow pace of life (3), animals } \\
\text { (3), fresh products (3), flowers (1), } \\
\text { rice (1), undeveloped (1), honey (1), } \\
\text { dog (1), etc. }\end{array}$ \\
\hline
\end{tabular}

Considering the results of the free associative experiment, it should be noted that the percentage of single-individual reactions provided by the Russian respondents is much higher than that given by the Chinese young adults. A similar tendency was observed in the first part of the experiment when the Russian respondents demonstrated much higher percentage of single-individual reactions to the wordstimulus CITY in comparison with the Chinese respondents. This fact may indicate that the Russian students' reactions appear to be more individual, thus related to their personal experience.

Despite the fact that most of the Russian and Chinese respondents speak in favour of living in the city, the reactions obtained show that their attitude to the village is on the whole positive and even romantic and enthusiastic to some extent. The young people, the representatives of the Russian and Chinese cultures, enjoy the beauty of nature, country's vast expanses, fresh products, freedom and fresh air. In this way, they contrast the village with the city and its ecological problems. In addition, both Chinese and Russian respondents emphasize the significance of the ecological parameter, which is reflected in the correlation between frequent reactions to the words-stimuli CITY and VILLAGE: traffic jams and pollution and clean air and nature respectively. Thus, it appears that today's young people associate the city and 
the village with the presence or absence of ecological problems. The ecological parameter represented by negative associations that are evoked by living in the city is reflected in a variety of positive associations to the word-stimulus VILLAGE. So, for the Russian respondents VILLAGE correlates with fresh air (20), nature (17), tranquility (10), quietness (10), natural food (7), berries and mushrooms (6), river (4), forest (4), etc. For the Chinese respondents VILLAGE is associated with fresh air (19), nature (10), forest (10), river (8), lake (6), trees (6), animals (5), few cars (4), milk (3), flowers (1), rice (1). On the whole, the percentage of positive reactions provided by the Russian and Chinese respondents is virtually identical. The reactions represented by lexemes with positive connotation make $57 \%$ and $56 \%$ of the total number of reactions respectively.

All the negative associations are related to the pragmatic aspect, which can be explained by the insufficient development of infrastructure, lack of job opportunities, low income, and domestic problems and are expressed by:

a) the collocations containing the lexemes with negative connotation such as poor (3), far from civilization (3), poor medical treatment (3), lack of essential things (3), poor goods supply at shops (3), far from the city (3), low pay (2), problems with transport (1) (the Russian respondents); poor road (12), uncomfortable transport (8), problems of public health service (4), slow pace of life (3) (the Chinese respondents);

b) combination of nouns with the indefinite numeral adjectives little / few or the negative particle no: little opportunity for professional development (5), no job (4), no hot water (2), no access to up-to-date information (1), few modern facilities (1), no infrastructure (1), no comfortable conditions (1) (the Russian students) and few shops (6), no opportunities to get education (4), no job (3) (the Chinese students).

c) single noun or adjective lexemes with negative connotation sometimes also containing negative prefix un: dirty (3) (The Russian respondents); sameness (6), uncomfortable (4), undeveloped (1) (the Chinese respondents).

It should be mentioned that the negative reactions by the Russian students are among peripheral ones and make up $18 \%$ of the total number whereas the negative reactions by the Chinese participants are greater in number and account for $32 \%$ of the total number of the associations provided. In general, these data correlate with the results obtained in the first part of the experiment where the Chinese students, expressing their reactions to the word-stimulus $C I T Y$, highlight the significance of comfortable living conditions. It appears that this fact may explain a higher percentage of negative reactions associated with the pragmatic perception of the village.

Figure 3 and Figure 4 show the nuclear features of the village, discovered in the course of the study, and demonstrate the close and remote periphery of the concept. 
Figure 3. Russian young adults' associations to the word-stimulus VILLAGE

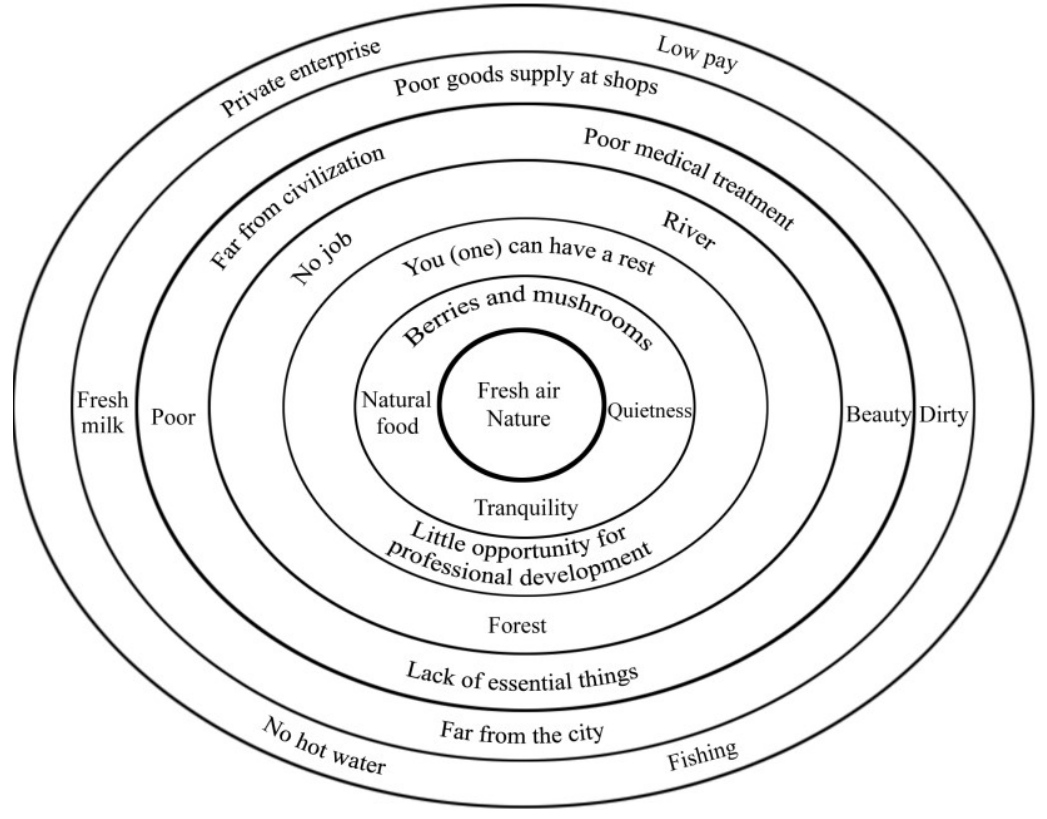

Figure 4. Chinese young adults' associations to the word-stimulus VILLAGE

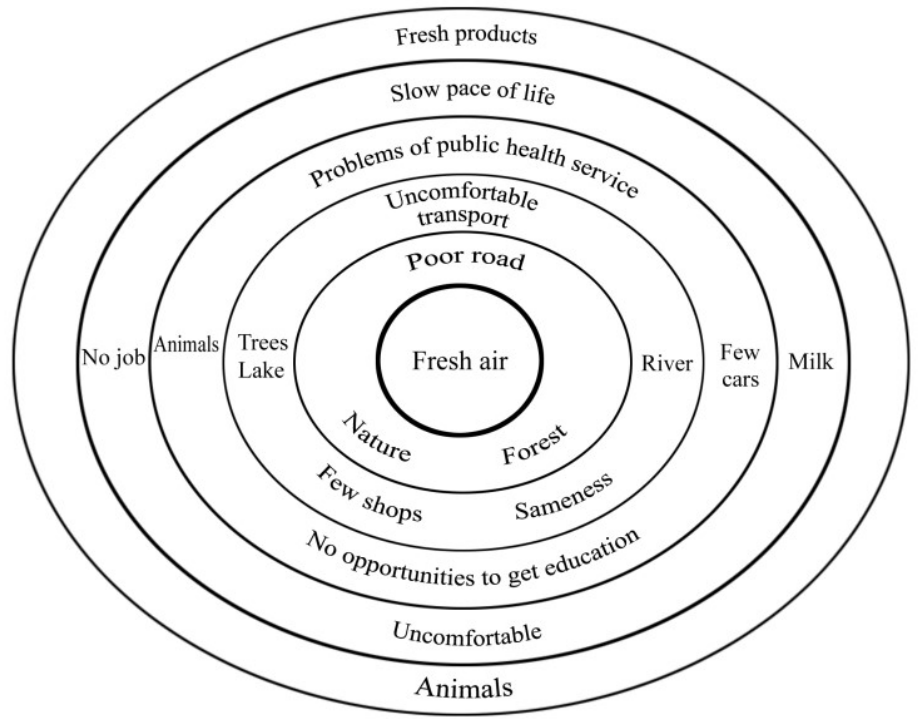


Another important point in the evaluation of the village from a pragmatic perspective is to reveal the respondents' perception of the place from the standpoint of prestige and status. For instance, while analyzing the Russian respondents' reactions, it was noticed that the parameter of prestige and status is represented by a rather limited number of ambivalent reactions. They are either negative, for example, far from civilization (3), stupid people (1), no job (4) or positive, for instance, private enterprise (2), less competitive (1), independence (1). The same tendency can be observed in the attitude of the Chinese young people to the village; still it may be concluded that most of their reactions characterize the village rather negatively (see above).

Finally, it should be mentioned that recreation as another significant aspect in the pragmatic assessment of rural living is also represented differently in the system of the Russian and Chinese respondents' associations. Thus, the Chinese young adults provide no associations that could directly characterize recreation in the village. This fact confirms that today's young people from China believe that the cultural sector and recreation in the village are not well developed, which could be one of many reasons for the youth's migration to town. Interestingly, the Russian respondents often associate the village with recreation, thus contrasting the village with the city and work associated with the latter. The following reactions by the Russian respondents are among pragmatic ones that characterize recreation in the village: you (one) can have a rest (5), fishing (2), fresh milk (3), beauty (3), festivals (1), hunting (1), outdoor activities (1), fishing rod (1), fires (1), buns (1), happiness (1), good spirits (1), apart from indirect reactions such as tranquility (10), quietness (10) etc. On the other hand, there is an insignificant number of reactions which emphasize the insufficient development of recreational activities, for instance, monotonous dull life (1), nowhere to go (1), loneliness (1).

Thus, according to the results obtained it can be stated that the perception of the village by the Russian and Chinese respondents is quite different on the one hand and is often realized through opposition to the city on the other hand. The difference mainly concerns pragmatic factors. The Chinese participants hardly regard the village as a good and perspective place in the aspect of career, recreation and comfort whereas the Russian respondents though realizing the disadvantages in the opportunities and facilities in comparison with the city still consider the village to be able to give them the possibility for self-realization in business due to low competitiveness as well as for recreation thanks to its unspoiled and quiet environment. Moreover, a large percentage of the Russian participants show great interest in the village as a place of rest and relaxation thus opposing it to the city. Besides, a small percentage of the Russian students express their readiness and even willingness to live in the village but situated close to the city so that it might be possible for them to commute to the city for work or to live in the village and take advantage of its benefits working via Internet.

Thus, it may be concluded that the similarity in the perception of the village by the Russian and Chinese respondents mainly lies in the fact that the representatives of both cultures imagine the village as an ideal place from the ecological point of view, but inconsistent living conditions and job prospects turn the balance in favour of the city.

\section{Conclusion}

The results of the present study are of dual significance for the present-day science:

1. They surely have lingvocultural importance as they are connected with the investigation and interpretation of the linguistic data and draw conclusions on the 
common and specific cultural features of the Russian and Chinese young adults' perception of the notions under study, i.e. the city and the village.

2 . They are also of applied and sociological relevance since they clearly show the direction of the development of the city and the village from the point of view of the younger generation which is to build the upcoming future.

Blending these together, it is possible to say that this study revealing the understanding of the Russian and Chinese young adults of the city and the village and demonstrating their attitude towards the notions at the same time manages to show the youth's desires, plans and perspectives underlying their future actions as well as give evidence on how interconnected the perception of a certain fragment of reality by different cultures might be and how influential the process of globalization is in modern world.

To go into details it is necessary to mention that the perception of the city by the Russian and Chinese respondents displays great similarity in that it is fully pragmatic. Thus, the representatives of both cultures completely realize the problems of modern city including poor environmental conditions and all the consequences that come with them such as bad health and improper quality of food, overpopulation which brings overcrowdedness, high competitiveness, traffic jams, etc. Nevertheless their positive impressions about the city still dominate as the young people of the two cultures are led by their hopes for the favourable succession of life events and prestige of city life. So, the Chinese and Russian students associate the city with greater job opportunities, higher standard living conditions, with the Chinese participants ranking these two as the ideas of paramount importance and the Russians putting emphasis on the employment together with recreation possibilities. Actually here we come to the point which marks the differences in the Russian and Chinese attitudes towards the city. The Chinese respondents express their desire to work, earn good money to ensure better living conditions putting the latter as their general aim. The Russian participants think more about recreation opportunities regarding good job and money as a means providing the opportunity to rest in quality.

What concerns the village, the results of the present study also demonstrate some similarity in its perception by the Russian and Chinese youth. To be more precise it is necessary to mention that positive responses of the representatives of both cultures mainly coincide and make the most of the total reactions. Besides, the Russian and Chinese young adults show stunning unanimity choosing the tendency to describe the village through its opposition to the city. Consequently, the village is positively assessed there where the city receives the largest number of negative responses and vice versa. For instance, young adults are optimistic in what concerns environmental conditions and represent the village as a tranquil and quiet place which is close to nature with fresh air. But the pragmatic responses related to the employment and living condition prospects show the young people's dissatisfaction with the infrastructure and amenities provided by the village. Strangely, the Russian participants having placed a great importance on the city's recreation aspect equally mark the village as a good place for alternative rest, thus, mostly regarding the village as a recreational area ensuring comfortable relaxation for urban dwellers. The Chinese respondents on the contrary "refuse" the village the possibility of providing good rest giving indirect responses which could only roughly refer to recreational parameter such as forest (10), river (8), lake (6) which compared with the Russian direct you (one) can have a rest (5), fishing (2), festivals (1), hunting (1), outdoor activities (1), fishing rod (1), fires (1) and indirect responses tranquility (10), quietness (10), natural food (7), berries and mushrooms (6), river (4), forest (4) makes certain difference.

Summing everything up, it may be concluded that the process of urbanization together with rural-urban migration will hardly stop both in Russia and China in the recent years. The young generation being extremely pragmatic in mind set their views 
to the city regarding it as a place which guarantees higher life standards in comparison with the village and thus appears more attractive for young people. There is no denying that this is an alarming tendency both for the village and the city. First, it predicts uncertain future to the village, the population of which may rapidly grow old and, as a consequence, some villages can disappear altogether. Second, the city apart from its ecological problems and overpopulation can come to new challenges connected with the lack of food produced by rural population. So, if nothing is changed in the near future, the world may have to face new serious problems.

\section{Acknowledgements}

This work is funded within the framework of realization of Strategic Programme on National Research Tomsk Polytechnic University Competitiveness Enhancement in the Group of Top Level World Research and Academic Institutions.

\section{Bibliographic references}

United Nations. Department of Economic and Social Affairs. Population Division. World Urbanization Prospects: The 2014 Revision, Highlights. ISBN 978 - 92-1151517- 6

LYNCH, K. 1960. The Image of the City. Cambridge Massachusetts: MIT Press. ISBN: 9780262120043

AVRAHAM, E. 2004. Media Strategies for Improving an Unfavorable City Image. In: Cities, 21(6), pp. 471-479.

EVANS, G., - SHAW, P. 2004. The Contribution of Culture to Regeneration in the UK: A Review of Evidence. London: DCMS.

GARCIA, B. 2004. Cultural Policy and Urban Regeneration in Western European Cities: Lessons from Experience, Prospects for the Future. Local Economy, 19(4), pp. 312-326.

GARCIA, B. 2005. Deconstructing the City of Culture: The Long-Term Cultural Legacies of Glasgow 1990. In: Urban Studies, 42(5-6), pp. 841-868.

DINNIE, K. 2010. City Branding: Theory and Cases. New York: Palgrave Macmillan. DUNCAN, J. S., - LEY, D. 2013. Place / Culture / Representation. New York and London: Routledge.

STRAUSS, A. L. 1968. (Ed.). The American City, a Sourcebook of Urban Imagery Text. Chicago: Aldine.

VAN DER RYN, S., - BOIE, W. R. 1963. Value Measurement and Visual Factors in the Urban Environment Text. Berkeley: Univ. of California, College of Environmental Design.

PILE, S. 2010. Emotions and Affect in Recent Human Geography. In: Transactions of the Institute of British Geographers, 35(1), pp. 5-20.

SLATER, T. - ANDERSON, N. 2012. The Reputational Ghetto: Territorial Stigmatisation in St. Paul's, Bristol. In: Transactions of the Institute of British Geographers, 37 (4), pp. 530-546.

APPLEYARD, D. 1970. Styles and Methods of Structuring a City. In: Environment and Behavior, 2, pp. 100-117.

CONNELL, J. - DASGUPTA, B. - LAISHLEY, R. - LIPTON, M. 1976. Migration from Rural Areas: The Evidence from Village Studies. Oxford University Press, Delhi.

FIREBAUGH, G. 1979. Structural Determinants of Urbanization in Asia and Latin America, 1950-1970. In: Annual Reviews Sociology, 44 (2), pp. 199-215.

KOREL, L. B. 1982. Population Movements between Urban and Rural Areas in Terms of Urbanization. Novosibirsk: Nauka.

ARUTYUNYAN, YU. V. 1995. Russians: Urban and Rural Citizens. Moscow: IEA. 
CHIZHIKOV V. M. 1999. Dialectics of Interaction of Socio-Cultural Systems of the Town and the Village. Moscow: MGUKI.

ZEGAR, Yu. S. 2009. Agriculture and the Village in the Period of Globalization. In: Proceedings of the Free Economic Society of Russia. Moscow, FEO of Russia, volume 99, №4, pp. 127-160. ISBN 978-5-94160-081-6

GRIGORIEV, S. I. 2010. Sociology of Vitality of the Russian Village and Villager at the Beginning of the 21st Century. In: Sociological Research, №6, pp. 39-44.

SHKERIN, A. V. 2012. Social Transformation of the Russian Village in the Context of Globalization. Nizhny Novgorod, 208 p.

TARASOVA, N. V. 1995. Rural-Urban Migration in Russia: Current Tendencies and Social-Demographic Consequences. In: Sociological Research, Moscow, №12, pp. 48-58.

GOLOVASCHENKO, K.S. 1996. Some Aspects of Rural Migration in Modern Russia. In: Some Problems of Socio-Political Development of Modern Russian Society, Saratov, pp. 124-129.

AKHIEZER, A. S. 2000. Dialectics of Urbanization and Migration in Russia. In: Social Studies Today, №1. pp. 78-89.

MKRTCHYAN, N. V. 2003. From Russia to Russia: Where do Internal Migrants Go from and to. In: Russian World, №2, pp. 151-164.

FLORINSKAYA, Yu. F. 2006. Labour Migration from Small Russian Towns as a Way of Survival. In: Sociological Research, №6, pp. 79-89.

NIKIFOROV, L. V. 2007. The City and the Village: the Integration Processes in the Soviet and Post-Soviet Periods. In: Journal of Social Policy Studies, volume 5, № 2, pp. 179-200.

PATSIORKOVSKII, B. B. 2010. Rural-Urban Russia. Moscow, ISESP RAS, 390 p. ISBN 978-5-89997-040.

MYMRINA, D. F. - ABDRASHITOVA M. O. 2015. The Concept of Hometown in German, Russian and Vietnamese Cultures (Experimental Studies). In: Mediterranean Journal of Social Sciences, vol. 6, № 3 S1, pp. 499-506.

OZHEGOV S. I. - SHVEDOVA, N. YU. 2010. Dictionary of the Russian Language. Moscow.

Cidian online dictionary. URL: http://cidian.xpcha.com/03dgcbnhqjx.html (access date: 13.08.2015).

Big Soviet Dictionary. URL: http://www.big-soviet.ru (access date: 13.08.2015).

UFIMTSEVA, N. V. 1996. The Experience of Yet Another Self / Ethno-Cultural Specificity of Language Consciousness. Moscow: Institute of Linguistics of RAS, pp. 139-162.

Words: 7205

Characters: 46832 (26,01 standard pages)

Dina F. Mymrina, PhD

Anastasia L. Khlebnikova

National Research Tomsk Polytechnic University

634050, prospect Lenina, 30, Tomsk

Russia

mymrina_df@tpu.ru,dina_mymrina@yahoo.com

anastasia22@ngs.ru

Svetlana L. Vasilyeva, PhD

Tomsk State University of Architecture and Building

634003, Solyanaya sq., 2, Tomsk

Russia 
vasilyeva_sl@mail.ru

Olga M. Zubkova

Tomsk State University

634050, prospect Lenina, 36, Tomsk

Russia

zetaolga@gmail.com

Sofia A. Chizhevskaya

Novosibirsk State University

630090, Novosibirsk, 2 Pirogova Str., Novosibirsk

Russia

dekanat@fija.nsu.ru,sophia.ch@yandex.ru 